\title{
The Impact Of Systemic Loss Given Default On Economic Capital
}

Jenni van Dyk, North-West University \& Centre for Business Mathematics and Informatics, South Africa Jaun Lange, North-West University \& Centre for Business Mathematics and Informatics, South Africa

Gary van Vuuren, North-West University \& Centre for Business Mathematics and Informatics, South Africa

\begin{abstract}
Empirical studies have demonstrated that loan default probabilities (PD) and loss given defaults (LGD) are positively correlated because of a common, business cycle, dependency. Regulatory capital requirements demand that banks use downturn LGD estimates because the correlation between PD and LGD is not captured. Economic capital models are not bound by this constraint. We extend and implement a model which captures the PD and LGD correlation by exploring the link between defaults and recoveries from a systemic point of view. We investigate the impact of correlated defaults and resultant loss rates on a portfolio comprising default-sensitive financial instruments. We demonstrate that the systemic component of recovery risk (driven by macroeconomic conditions) exerts greater influence on loss estimation and fair risk pricing than its standalone component.
\end{abstract}

Keywords: Probability Of Default; Loss Given Default; Correlation; Economic Capital; Expected Loss

\section{INTRODUCTION}

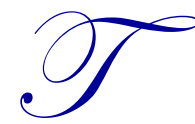

he credit crisis of 2008 demonstrated dependency between default risk and recovery risk (Li \& Tunay, 2012). Many standard economic capital (EC) models are deficient as they do not account for such dependency and ignoring this reliance can lead to a significant underestimation of the risk associated with a loan portfolio (Elizalde \& Repullo, 2007). Credit risk underestimation was a principal reason for the subprime crisis as regulators and industry participants severely underestimated the exposure of financial institutions, including those perceived to be financially stable such as Bear Sterns and Lehman Brothers (Jürgenson, 2015).

Catastrophic failures of inadequate capital allocation and management were exposed and culpability for the cause, severity and duration of the crisis was placed on, inter alia, regulatory bodies, credit rating agencies and bank CEOs (Esterhuysen, van Vuuren, \& Styger, 2011). As a result, financial institutions began to question both the soundness and relevance of the credit risk principles outlined in the Basel II Accord issued by the Basel Committee on Banking Supervision (BCBS) (BCBS, 2006). The Basel II accord's methodology for calculating credit risk has been criticised as too complex, potentially permitting capital allocation arbitrage and encouraging negligent lending standards (FDIC, 2004, van Laere \& Baesens, 2012 and Ho, 2012).

The focus of this paper is to investigate these regulatory criticisms by examining the link between defaults and recoveries from a systemic point of view as suggested by Li \& Tunay (2012). The impact of correlated defaults, and the consequent bond and loan portfolio loss rates is also explored.

Standard EC models used by financial institutions ignore the link between default risk and systemic recovery risk (Elizalde \& Repullo, 2007). An accepted, but ineffective, solution to account for this dependency is to capture and record downturn Loss Given Default (LGD), i.e. a mark-up of the LGD factor. The systemic part of recovery risk driven by macroeconomic conditions, however, has been found to have a more substantial impact than downturn LGD on loss estimation and risk pricing (Li \& Tunay, 2012). Financial institutions are also undercapitalised when following Basel regulatory requirements for the estimation of expected losses (EL) so, to accurately reflect the impact of systemic risk, EC models must take this link into account (Li \& Tunay, 2012). We expand on Li \& Tunay's (2012) findings by stress testing their model. 
The rest of this paper proceeds as follows: Section 2 provides a literature review governing the relevant background material such as the origin and development of regulatory and economic capital. Section 3 explains the data used and the methodology followed and includes all of the important mathematics used in the exposition. Simulation results are presented in Section 4 along with a discourse about these findings and consequences for banks. Section 5 concludes.

\section{LITERATURE SURVEY}

This section comprises four subsections. The first two focus on distinguishing between regulatory capital (RC) and EC. Regulatory model shortcomings are then outlined in the third subsection and how these may be overcome using an EC model. The final subsection shifts the focus to LGD and the role it plays in both RC and EC.

\subsection{Regulatory Capital}

Credit risk gives rise to two types of losses, known as EL and Unexpected Losses (UL) (Curcio \& Gianfrancesco, 2009). The borrower's PD and the LGD determine the level of EL. If the assumption is made that PD and LGD are independent, the expected loss rate (ELR) for a single loan/borrower $j$ is given by the product: $P D_{j} \times L G D_{j}$ (Curcio \& Gianfrancesco, 2009). For a complete credit portfolio, the aggregate ELR is the sum of the individual loan ELRs. Since they are expected, these losses must be hedged by adequate accounting loan-loss provisions and represent the physical cost of bank lending activity. Credit risk is identified by actual losses that are potentially greater than these EL (Saita, 2003), also known as UL, and are partly covered by a bank's capital. Banks have to set aside an amount of $\mathrm{RC}$ to face the risk of UL, deviating these resources from their lending activity and suffering from the consequent opportunity cost.

The first set of minimum capital requirements for banks, known as the Basel I Accord, was published in 1988 by the Bank for International Settlements (BIS). A minimum capital requirement was set at $8 \%$ of risk-weighted assets (RWA) (BCBS, 1988) regardless of the creditwortiness of the borrower and collateral strength of the loan (Gordy \& Howells, 2006). Thus, the RWA failed to capture the true economic risk and led to banks reducing their regulatory capital requirements with little or no corresponding reduction in their overall economic risks, i.e. RC arbitrage (Jones, 2000). This led to a revised capital framework known as Basel II which was endorsed for publication by the G-10 central-bank governors and heads of supervision in 2004 (McNeil, Frey, \& Embrechts, 2015). The primary purpose of Basel II was to further align RC requirements with EC (Gordy \& Howells, 2006), i.e. to make RC more risksensitive while retaining its simplicity and transparency as a risk measure. Furthermore, Basel II aimed at developing a "framework that would further strengthen the soundness and stability of the international banking system" (BCBS, 2006). The minimum capital requirement remained at $8 \%$ of RWA, as in Basel I (BCBS, 2006).

Capital requirements represent the quantity of capital that is required to mitigate and contain losses while meeting banks' liabilities $(\mathrm{Ho}, 2012)$. The purpose of capital is to prevent the liquidation or bankruptcy of financial institutions as it provides a buffer against insolvency. The collapse of Lehman Brothers and the subsequent financial crisis of 2008 demonstrates the significance of sufficient capital requirement.

Financial institutions are obligated to set aside a minimum amount of capital as specified by the domestic regulator. These regulations are usually inferred from the Basel Accord made public by the Bank for International Settlements (BIS). This form of capital, referred to as RC, serves to protect the institution from defaulting in economically stressed periods. Furthermore, by imposing high capital levels, small investors are protected and potential systematic effects of bank failure are countered (Richardson \& Stephenson, 2000). However, RC is not enough to convince investors that their money is safe, thus an internal assessment of capital is determined over and above RC; this is the economic capital which is known as EC (Klaassen \& van Eeghen, 2009). RC is estimated at a transaction level based on RWA with PD, LGD, Exposure at Default (EAD) and remaining maturity as inputs and is designed to ensure the stability of the entire system.

The Basel II framework employs a "three pillars" concept. Banks are required to calculate RC under Pillar 1 with the objective of computing a figure that is a more realistic representation of the financial institution's loss potential. Pillar 2 sets requirements for supervisory review emphasising the necessity to provide an internal overview of risk exposure. Lastly, in order to diminish systemic risk, Pillar 3 obliges financial institutions to be transparent and disclose risk 
measures and other relevant risk information (McNeil, Frey, \& Embrechts, 2015). Basel II sets forth two approaches for calculating the RC charge, namely, the Standardised Approach and the Internal Ratings-Based (IRB) approach (BCBS, 2006). In the former approach risk weights are dependent on an external rating provided by an external credit rating agency, whereas the latter differentiates to a larger extent within credit risk and thus significantly reduces the incentives to engage in regulatory capital arbitrage (van Laere \& Baesens, 2012). The IRB approach allows banks to use internally-developed models to determine the values for input parameters.

Benston \& Kaufman (1996) argue that modern financial systems defy effective regulation. Regulation increases both the cost to the bank and to the user without necessarily increasing the safety and stability of the financial institution. Capital regulation is both unnecessary and incapable of improving banks' capital position more than banks could do on their own (van Laere, 2012). Dowd's (1996) argument for financial laissez-faire (free-banking) also supports the standing that regulation is meaningless, but infeasible after the detrimental effects of the 2008 financial crisis.

A principal objective of banks is to maximise shareholder value despite the regulatory restrictions imposed. Financial institutions should not, however, depend on regulatory measures as the only method of mitigating their risk (van Laere \& Baesens, 2012). It remains highly contested as to whether a risk based capital ratio, as suggested by the regulatory framework, is the ideal tool to mitigate bank risk (van Laere \& Baesens, 2012). An additional controversy of RC models is that RC can be considerably different from the actual capital level determined by sophisticated risk-based capital methodologies (Ho, 2012). The under or overcapitalisation of companies are the result of this controversy. Secondly, RC is not as effective as EC in facilitating risk-based decisions. Jacobs \& van Vuuren (2014) observed that EC is a more risk-sensitive measure and should replace Pillar I RC. Lastly, Ho (2012) is sceptical whether periodic capital reporting to the regulator will suffice to prevent defaults of financial institutions in times of crises. According to Tiesset \& Trousard (2005), RC is not designed to capture all types of risks, or to measure their actual levels, and is thus misleading to unsophisticated users (Tiesset \& Trousard, 2005).

\subsection{Economic Capital}

While RC requirements are imposed on institutions, the notion of EC has broadened over the past years (since 2010), from risk and performance measurement to the determination of bank capital adequacy (van Laere \& Baesens, 2012). Differing definitions have been proposed for EC, where EC may be calculated by determining the capital amount needed to ensure that a bank will stay solvent for a set period, given its risk appetite (Ho, 2012). Jackson, et al. (2012) define EC as the process of calibrating internal EC models to reflect their current external credit rating - therefore holding sufficient capital to maintain their current credit rating as perceived by external rating agencies. Elizalde \& Repullo (2007) believe that EC should not be calculated with a certain credit rating in mind, but rather from an underlying objective function such as bank value maximisation. EC may therefore be defined as the capital that would likely be held by bank shareholders in the absence of RC. EC may also be thought of more as a measure of risk, than of capital held. Traditional capital adequacy measures link capital to assets (or a form of adjusted assets), whereas EC relates capital to risks: the existence of assets is immaterial. Because EC is based on a probabilistic evaluation of possible future losses, it is often considered a forward-looking measure of capital adequacy. It has been argued that the assembly and deployment of robust EC models can better equip banks to anticipate potential problems (FDIC, 2004). EC model outputs are different from alternative capital adequacy estimates since they represent the physical capital required to adequately support the specific risks taken on by the bank.

The broadening of the definition of EC is partly brought about by Pillar 2 of Basel II, where supervisors require banks to rely on internal models to assess capital adequacy, but also by rapid changes in risk quantification and greater complexity of portfolios. EC is a risk measure that does not address the amount of capital held; it coexists with accounting and RC calculations (van Laere \& Baesens, 2012). EC is mainly used for internal risk management purposes, but has varying applications. The relevance and usefulness of EC depends on the extent to which senior management realises the importance of the EC measures (BCBS, 2006). The credit risk EC framework can recognise concentration risks and diversification benefits that arise from regional and industrial diversification. As a result, EC better reflects the actual risks embedded in transactions than RC (van Laere \& Baesens, 2012). 


\subsection{Model shortcomings}

The BCBS require that EL is calculated using (BCBS, 2006):

$$
E L=P D \cdot L G D \cdot E A D
$$

Implicit in (1) is that the PD and LGD are uncorrelated. Furthermore, the BCBS supposes that LGD is static and is not influenced by the state of the economy. Li \& Tunay (2012), however, proposed a methodology which allowed for stochastic variation of the LGD, whilst simultaneously incorporating systemic risk. This proposal results in an increased EL which has further implications for the UL and EC, as observed in Figure 1. This implication is investigated throughout this paper.

Figure 1. The distribution of credit losses with the Basel definitions of UL, EL and total loss (at a prescribed confidence level) indicated.

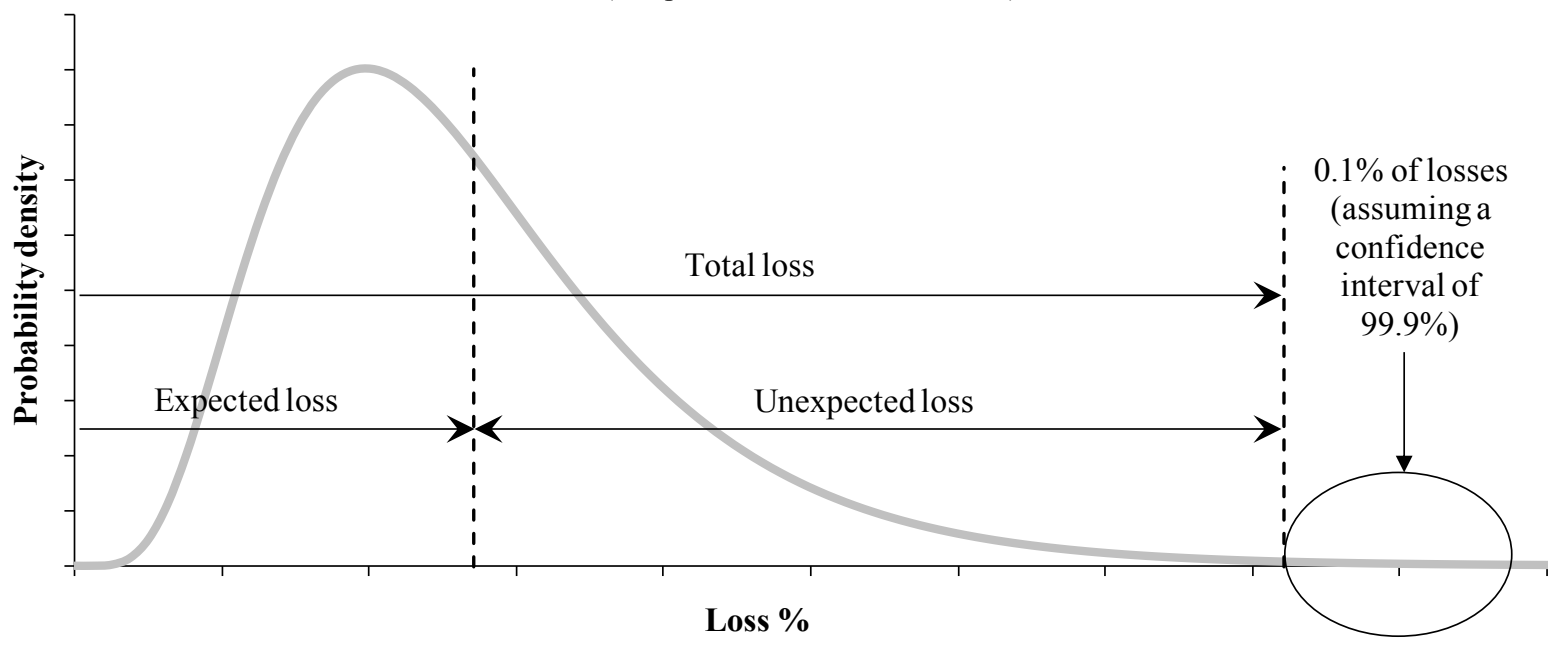

\section{$2.4 \quad$ Loss Given Default}

By definition, a debt instrument can only experience a loss if there has been a default and typically a default occurs when any of the following conditions are met (Schuermann, 2004):

- a loan is placed on non-accrual;

- a charge-off has already occurred;

- the obligor is more than 90 days past due and

- the obligor has filed for bankruptcy.

The LGD with respect to a loan is then usually defined as the ratio of losses to EAD (Schuermann, 2004). Average losses over extended periods of time can underestimate loss rates in an economic recession and can therefore lead to an underestimation of UL. LGDs should therefore be conditioned on a recession scenario in order to reflect the loss rates experienced during a severe downturn (Tiesset \& Trousard, 2005).

Tiesset \& Troussard (2005) argue that, unlike the case for PDs, regulators do not specify a formula for calculating conditional LGDs. It is up to the banks to provide estimates of LGD that are sufficiently conservative, reflecting loss rates in economic recessions, and taking into account possible correlations between PD and LGD in different portfolios. A modelling pitfall is to ignore a form of a systematic risk while measuring LGD (Frye, 2004). LGD has been defined as an economic concept, but it must be measured in some way using data that can be observed. This 
pitfall may be overcome by the work of Li \& Tunay (2012) who proposed taking into account economic downturn systemic effects.

Li \& Tunay (2012) state that financial institutions are undercapitalised when following Basel regulatory guidance to calculate EL and suggest that in order to accurately reflect the impact of systemic risk, EC models must take this link into account. We expand on Li \& Tunay's (2012) findings by stress testing their model.

\section{DATA AND METHODOLOGY}

The methodology proposed by Li \& Tunay (2012) was applied and investigated in this paper. This methodology is described below.

Assuming that the portfolio under investigation consists of $N$ exposures to $n$ borrowers, the Vasicek (2002) framework (as proposed by Basel II) is implemented to calculate inherent default correlations. Default occurs when the asset value of a borrower is less than its total debt value, i.e. the assumptions on which the Merton model is based were used (Wang, 2009).

Knowledge of the state of the overall economy, denoted by $X$, is required to determine the correlation between defaults of borrowers. Mathematically, the Vasicek (2002) framework is expressed as:

$$
A_{i}=\sqrt{\rho} X+\sqrt{1-\rho} \varepsilon_{i}, i=1,2, \ldots, n
$$

where $A_{i}$ is the asset return, $\rho$ is the common correlation between all borrowers $X$ and $\varepsilon_{i}$ are independent standard normal variables. $A_{i}$ consequently, also has a standard normal distribution. In the Vasicek (2002) framework, a borrower with annual PD will default over a period of one-year if its asset return is less than $\Phi^{-1}(P D)$, where $\Phi$ is the cumulative distribution function of the standard normal distribution. The probability that the percentage loss is smaller than $x$ for the Vasicek (2002) model is given by (3):

$$
\operatorname{Pr}(L \leq x)=\Phi\left(\frac{\sqrt{1-\rho} \cdot \Phi^{-1}\left(\frac{x}{\overline{G D}}\right)-\Phi^{-1}(p)}{\sqrt{\rho}}\right)
$$

Both Basel II and III assume a static LGD in the calculation of RC (BCBS, 2006 and BCBS, 2013), but for EC purposes treating LGD as a constant ignores the uncertainty surrounding the recovery once a borrower defaults on its obligations (Li \& Tunay, 2012). Consequently, an underestimation of EC for a specific target credit rating is the result. Vendors have recognised this shortcoming and have suggested modelling LGD as a stochastic random variable.

The Beta distribution has become the industry standard for simulating recovery at instrument level (Li \& Tunay, 2012). However, the dependence of the recovery on the macro economy, or $X$, is still lacking in these models. Pykhtin (2003), Frye (2004) and Barco (2007) have proposed models that account for this deficiency.

It is a common approach to model LGD as a normal or lognormal variable, however, this allows for LGD values to breach the sensible range of $[0,1]$. Sen (2008) modelled the LGD value as a discrete distribution, i.e. Sen (2008) asserted that a low recovery is always associated with a "bad" state of economy. Thus, the same risk driver is used for both default and recovery processes and the possibility of default-free loss or recovery is overlooked. Furthermore, discretising LGD does not accurately reflect a continuous, evolving economy.

The Beta distribution is more suited for modelling LGD because it is a distribution defined for values between 0 and 1 , it can take on many forms depending on its two parameter inputs and lastly, it is used in industry. The density of Beta distribution is given by:

$$
f(x, a, b)=\frac{1}{B(a, b)} x^{a-1}(1-x)^{b-1}, \quad 0 \leq x \leq 1,
$$


where $a>0$ and $b>0$ are the two parameters and

$$
B(a, b)=\frac{\Gamma(a) \cdot \Gamma(b)}{\Gamma(a+b)}
$$

is the Beta function. The mean of the distribution is:

$$
\mu(a, b)=\frac{a}{a+b}
$$

and its variance:

$$
\sigma^{2}(a, b)=\frac{a b}{(a+b+1)(a+b)^{2}}=\frac{\mu(\mu-1)}{a+b+1} .
$$

Thus, the Beta distribution can be re-parameterised using its mean $\mu$ and volatility parameter $k=a+b+1>0$, as $a$ and $b$ can be written as functions of $\mu$ and $k$ :

$$
\begin{aligned}
& a=(k-1) \mu, \\
& b=(k-1)(1-\mu)
\end{aligned}
$$

For any given value of the mean of LGD $\mu$, the bigger the $k$, the smaller the variance of LGD. The methodology for stochastically modelling the LGD follows.

A normally distributed asset return driven by the state of economy $X$, as in (2), is used to model defaults while a Beta distribution, as in (4), is used to model LGD. Thereafter the LGD is linked to $X$, such that high LGD values are accompanied by high default rates. This is achieved by generating an economy-dependent LGD factor and thereafter the use of percentile-to-percentile mapping to transform it into a Beta-distributed variable.

Mathematically, a normal variable $\left(Y_{j}\right)$ denoting the LGD factor is generated using:

$$
Y_{j}=-r X+\sqrt{1-r^{2}} e_{j}
$$

where $X$ is the same standard normal variable used in (2) and $e_{j}$ is a standard normal variable, independent of $X$, denoting the idiosyncratic LGD factor of defaulted facility $j$, and $r$ determines the extent to which the state of the economy affects the LGD rate. It is important at this point to distinguish between $\rho$ and $r$.

The percentile-to-percentile mapping of $Y_{j}$ to an LGD value in (5) is achieved by supposing that the LGD factor is the $p^{\text {th }}$ percentile of the standard normal distribution. The mapped LGD value is such that it is the $p^{\text {th }}$ percentile of the Beta distribution. A negative sign in front of the first term is a prerequisite as it causes higher LGD rates to be associated with unfavourable states of the economy. This means that when the economy is in a downturn, recovery rates decrease and LGD value tends to be higher (Li \& Tunay, 2012). Thus, $r$ measures the linkage between default rate (PD) and LGD rate. A Gaussian copula was used to capture this PD and LGD correlation, and the joint CDF of the normal distribution for the asset return, $A$. In addition, the Beta distribution for loss severity $L G D$ is given by

$$
\begin{aligned}
& F(z, w)=\operatorname{Pr}(A \leq a, L G D \leq w) \\
& =\Phi_{\Sigma}\left[a, \Phi^{-1}\left(F_{\mu, k}(w)\right)\right]
\end{aligned}
$$


where $\Phi$ denotes the cumulative distribution function (CDF) of a standard normal distribution, the $\Phi_{\Sigma}$ denotes the $\mathrm{CDF}$ of a bivariate normal distribution with zero mean and covariance matrix

$$
\Sigma=\left(\begin{array}{cc}
1 & -\sqrt{\rho r} \\
-\sqrt{\rho r} & 1
\end{array}\right)
$$

and $F_{\mu, k}(\cdot)$ is the CDF of the Beta distribution with mean $\mu$ and parameter $k$.

The PD-LGD correlation can be determined empirically. For a portfolio with historical PDs and LGDs, $r$ is chosen as the Spearman's $\rho$ that is the same for the simulated as well as the historical PDs and LGDs.

The procedure for such a calibration is: for a given $r$,

1. simulate PDs of the portfolio and LGDs for the defaulted issues for one year,

2. calculate the PD of the portfolio as the number of defaults divided by the number of obligors in the portfolio, and thereafter calculate the EAD-weighted LGD rate for defaulted issues,

3. repeat steps 1 and 2 to simulate PDs and LGDs for numerous time periods. Then

4. calculate Spearman's $\rho$ between these simulated PD and LGD rates and

5. finally, using an iterative trial-and-error approach, adjust $r$ until the $\rho$ matches for both simulated and historical PDs and LGDs.

Using a Monte Carlo simulation, the impact of this correlation on EC is investigated, where EC is defined as the difference of the percentile and the expected loss. The Monte Carlo simulation could be carried by following these steps:

1. draw the state of economy $X$,

2. for borrower $i$, draw an idiosyncratic factor $\varepsilon_{i}$ and calculate $A_{i}$,

3. calculate $\Phi^{-1}\left(P D_{i}\right)$. Borrower $i$ will default over the one-year period if $A_{i} \leq \Phi^{-1}\left(P D_{i}\right)$,

4. for each exposure to the borrowers that have defaulted, generate idiosyncratic $L G D$ factor $e$ and then calculate $\gamma$ in (2). Then

5. determine $p=\Phi(\gamma)$.

6. Generate an LGD value from the Beta distribution (4), such that $\operatorname{Pr}(W \leq L G D)=p$, where $W$ is the Beta variable with known mean $\mu$ and parameter $k$.

7. Calculate loss of each defaulted exposure using $E A D \times L G D$, where $E A D$ is the exposure size.

8. Calculate the total losses of all the defaulted exposures, and

9. repeat steps 1 to 8 to generate a portfolio loss distribution.

The average loss and the percentile corresponding to the confidence level required by the desired rating of the bank is then determined.

\section{RESULTS AND DISCUSSION}

The assumption was made that the asset correlation, i.e. $\rho$, is unlikely to exceed 0.25 based on Basel recommendations (BCBS, 2006). The BCBS specify asset correlations, these are not user-defined parameters. The maximum value specified by the BCBS (for some loan types these correlations are PD-dependent) is 0.24 .

Other variables were also kept constant (while $\rho$ and $r$ were isolated and allowed to vary) so as to explore the effect of the economy on EL. These static variables and the rationale behind their selection were:

- average LGD $\mu=40 \%$ (average LGDs are usually chosen as $40 \% \leq L G D \leq 50 \%$, BCBS (2006)),

- LGD variance $\sigma^{2}=4 \%$ (giving a reasonable standard deviation of $20 \%$ )

- $\mathrm{PD}=3 \%$ (this would be considered a high PD in most banks) and

- $\mathrm{EAD}=1$ (for simplicity). 
As discussed in the previous section, Li \& Tunay (2012) use a Beta Distribution to model stochastic LGD and thus incorporate the influence of the economy, as opposed to Basel methods that ignore this economic influence. The Beta distribution can take on various forms as input parameters change. Figure 2 illustrates the bimodal behaviour of the Beta distribution as the variance of the distribution is adjusted. This U-shaped density for the LGD, (i.e., with high probability mass at $0 \%$ and 100\%) has been observed by Dermine \& de Carvalho (2006) and Bastos (2010), who demonstrated this U shape empirically.

Figure 2. Bimodal behaviour of the Beta distribution.

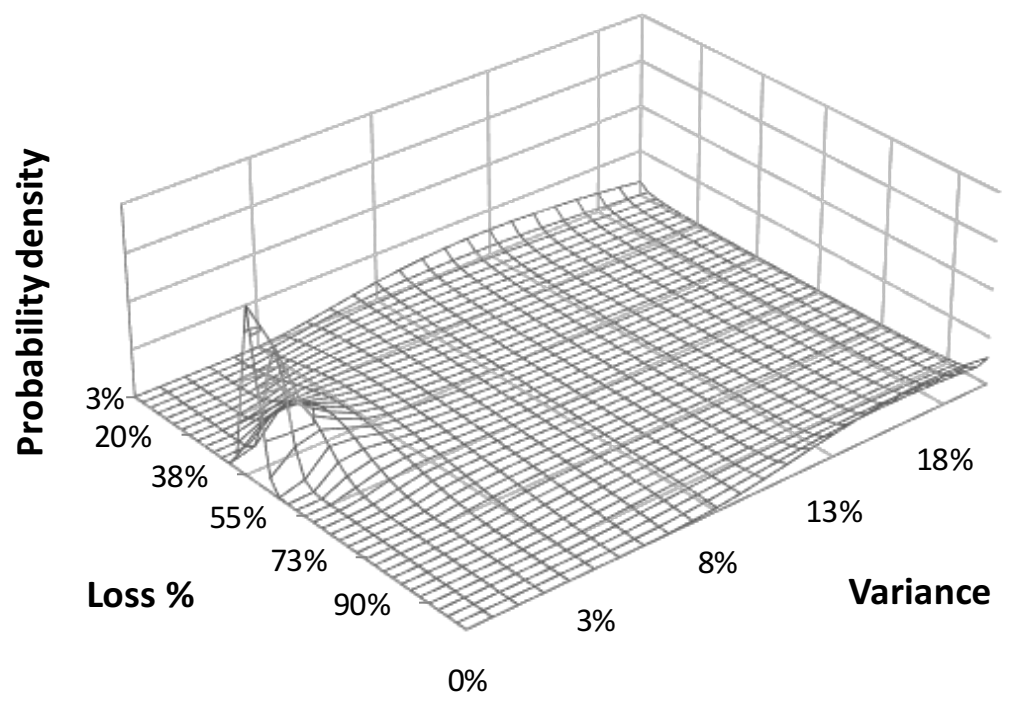

Increasing values of asset correlation, $\rho$, and macro-economic loan correlations, $r$, have no observable effect on the Basel EL (Figure 3) as shown in (1) (which is independent of both effects). Recall that Basel ELs ignore the impact of the economy on loan losses.

Figure 3. EL using Basel approach.

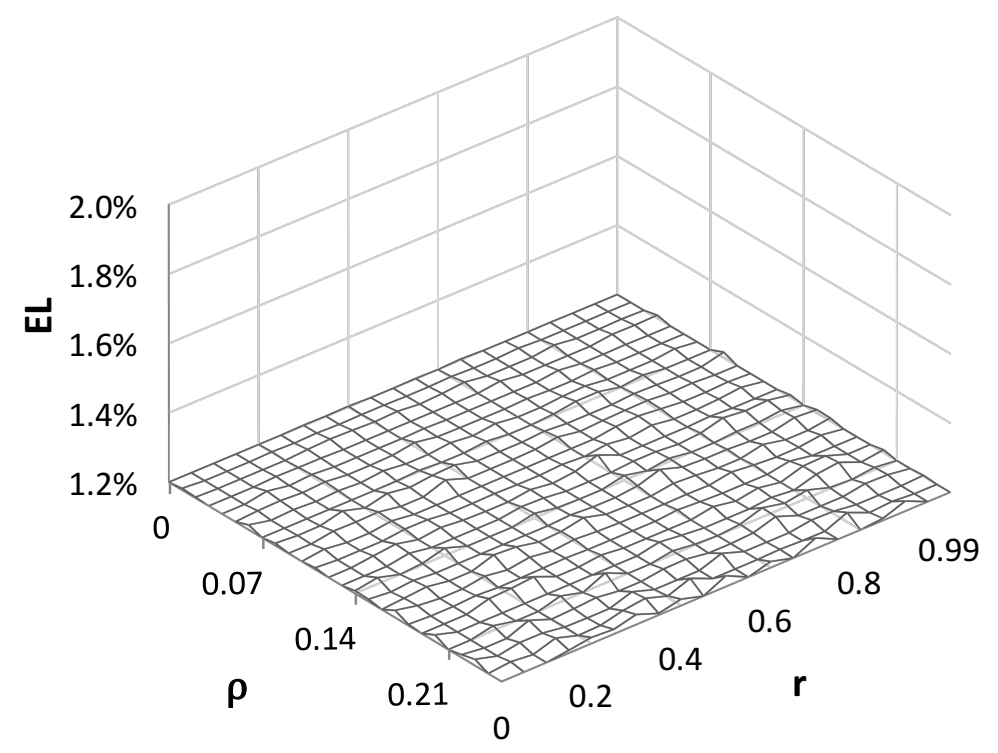


As $\rho$ and $r$ increase, significant impact on LT ELs are registered, as shown in Figure 4. Both asset correlations $(\rho)$ and macro-economic loan correlations, $r$, increase the EL.

Figure 4. EL using LT approach

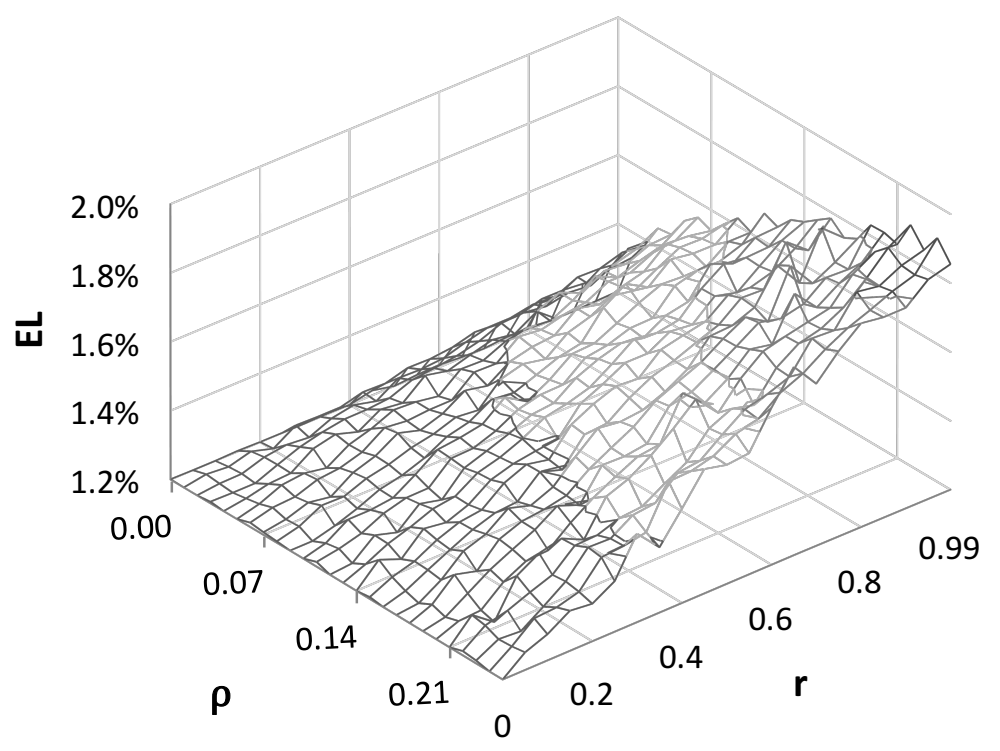

The isolated influence of $\rho$ and $r$ on LT EL is given in Figures 5 and 6 respectively.

Figure 5. LT EL for changes in $\boldsymbol{\rho}$.

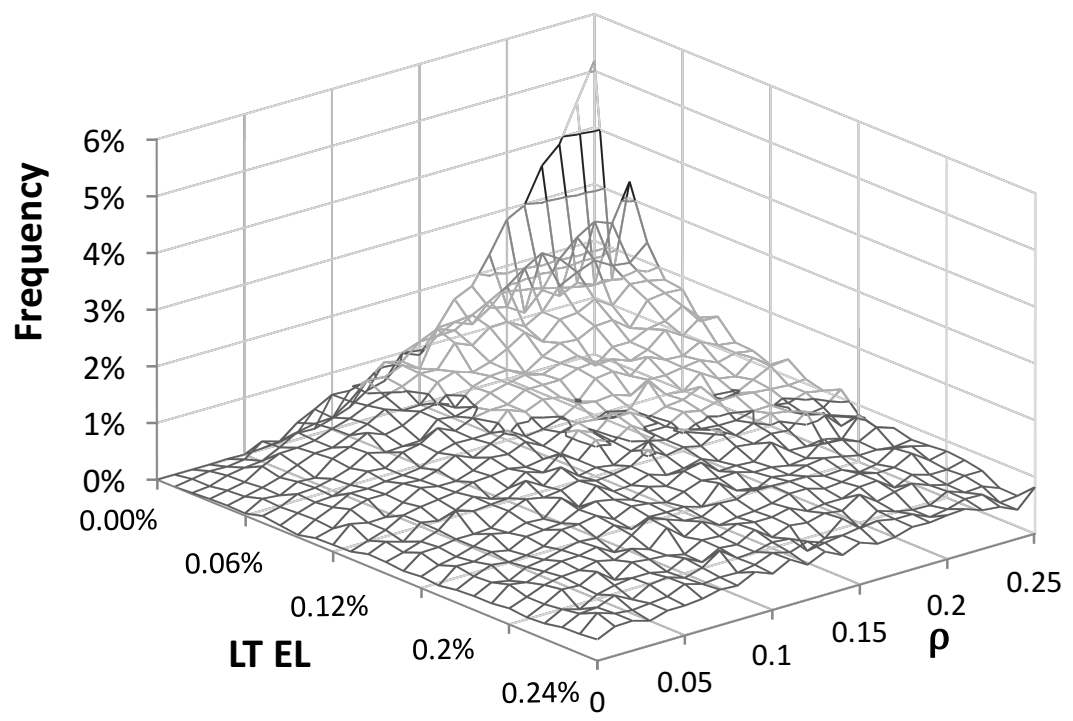


Figure 6. LT EL for changes in $\boldsymbol{r}$.

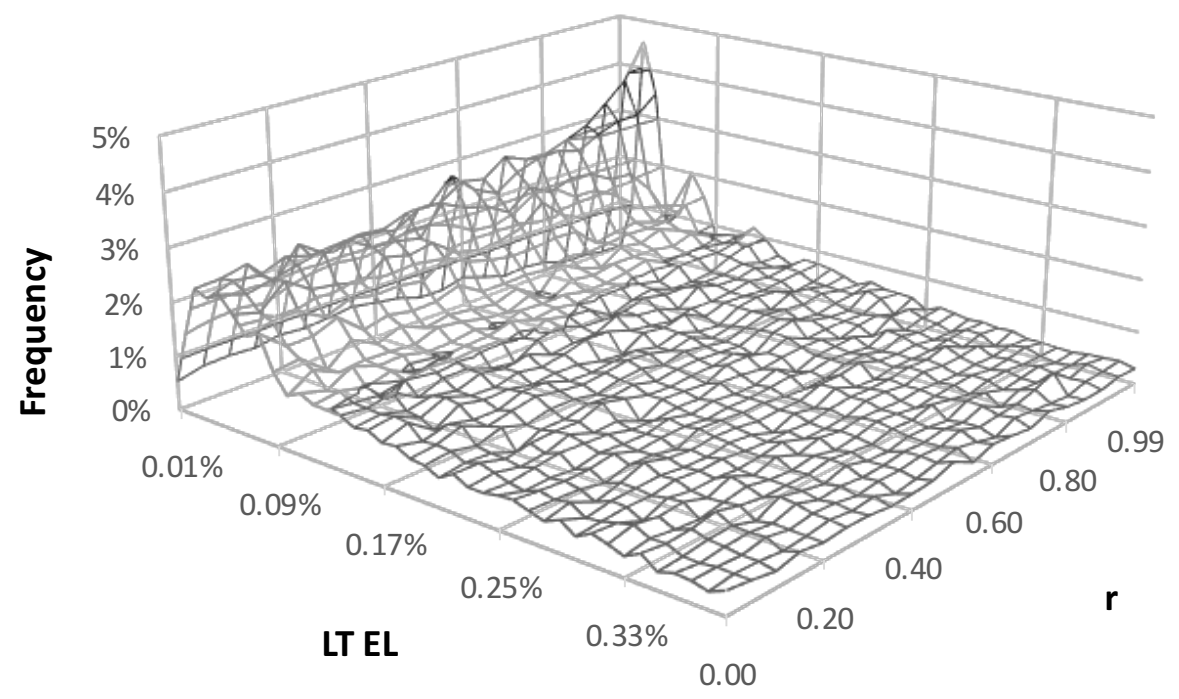

Contrary to Basel EL, LT EL takes the state of the economy and the combined interaction between $\rho$ and $r$ into account, which in turn leads to higher EL values. As $\rho$ and $r$ increase, the frequency of lower EL values increase. This is true for both $\rho$ and $r$, but the combined effect (in Figure 4) demonstrates the importance of the LT model, as the LT EL then increases significantly.

LT and Basel produce similar results for a macro-economic loan correlation, $r$, of less than $1 \%$. However, as $r$ breaches the $1 \%$ limit the EL for LT becomes considerably higher than that of Basel. Highly correlated loans will exhibit similar behaviour that is reflective of the economy in that point in time. Thus, in an economic downturn loans with a high $\rho$ would be expected to have a higher frequency of defaults, whereas with a more diversified loan portfolio the state of the economy has a less pronounced impact.

Figure 7 shows the effect of $\rho$ and $r$ on the Basel UL. It is clear that $r$ does not impact the Basel UL. A linear relationship exists between Basel UL and $\rho$ for the full range of $r$. 
Figure 7. Basel UL as a function of $\boldsymbol{\rho}$ and $\boldsymbol{r}$.

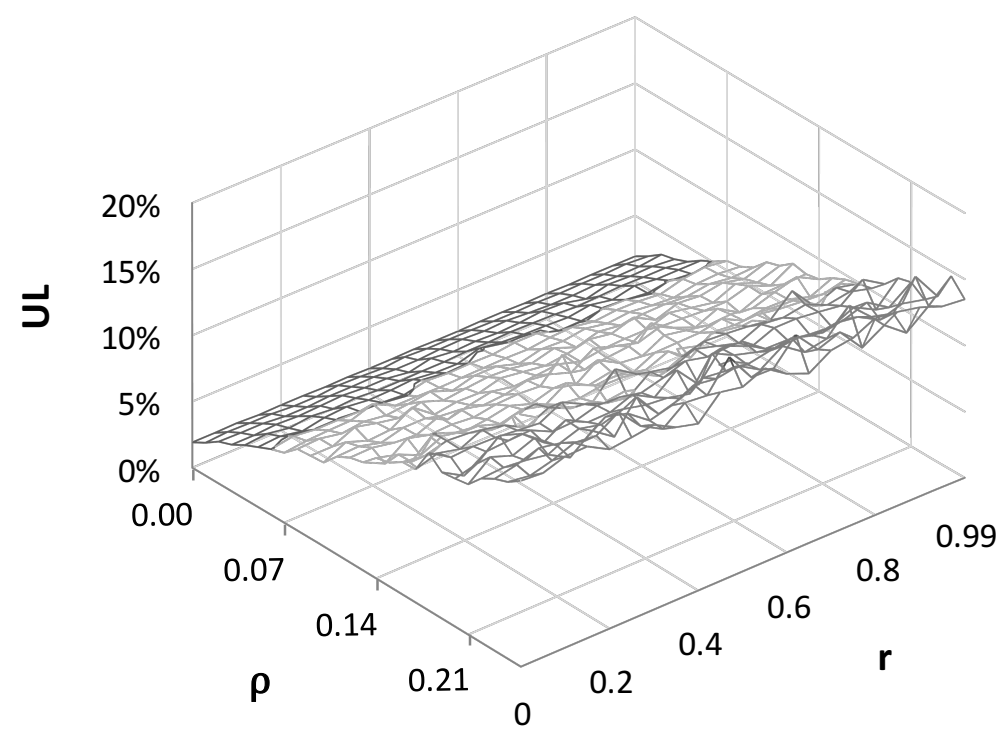

The LT model accounts for the state of the economy and this contributes significantly to the LT UL as shown in Figure 8. The gradient of the linear relationship between LT UL and $\rho$ increases for higher values of $r$. Since this model incorporates $r$, a previously ignored interaction between $\rho$ and $r$ is now accounted for and results in higher values of UL than those determined using the Basel approach. For high values of $r(r \geq 0.8)$, the LT UL is roughly double that of Basel's.

Figure 8. LT UL as a function of $\boldsymbol{\rho}$ and $\boldsymbol{r}$.

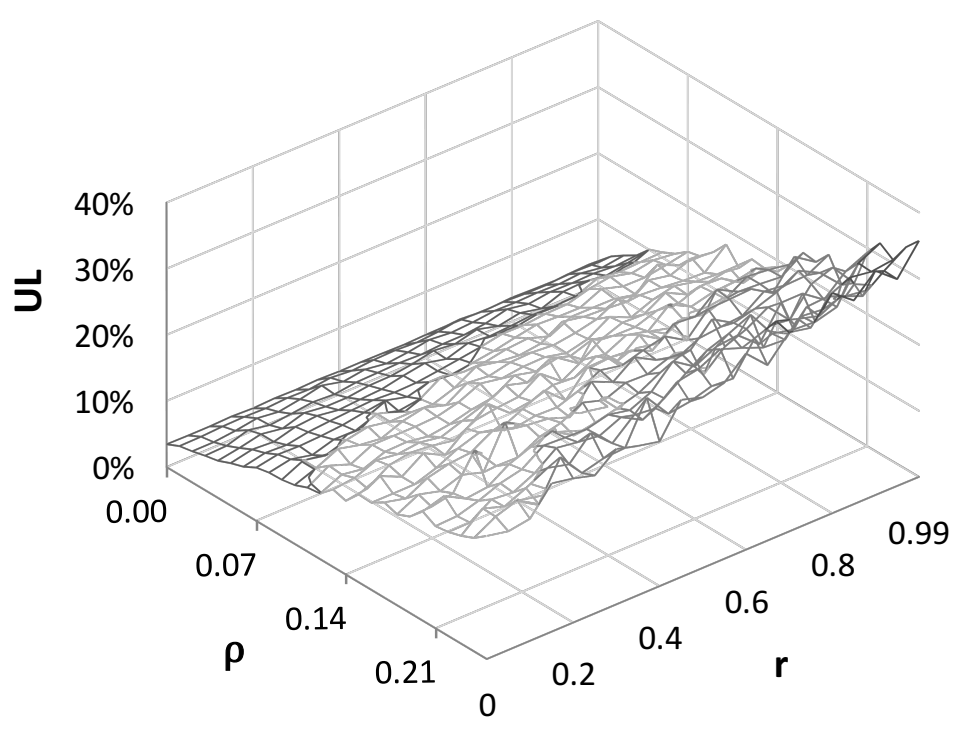

Figure 9 isolates two extreme value of $r$, namely $r=0.00$ and $r=0.99$ and shows the effect of increasing $\rho$ on (a) Basel UL and (b) LT UL. There is no impact on Basel's UL - regardless of $r$ used, but for the LT UL, results for extreme value of $r$ differ substantially. As the macro-economic correlations increase (i.e. systemic significance increases), the LT UL increases proportionately. 
Figure 9. Effect of $\boldsymbol{r}$ on UL using the (a) Basel approach and (b) LT approach.

Vertical scales are the same to illustrate the difference.
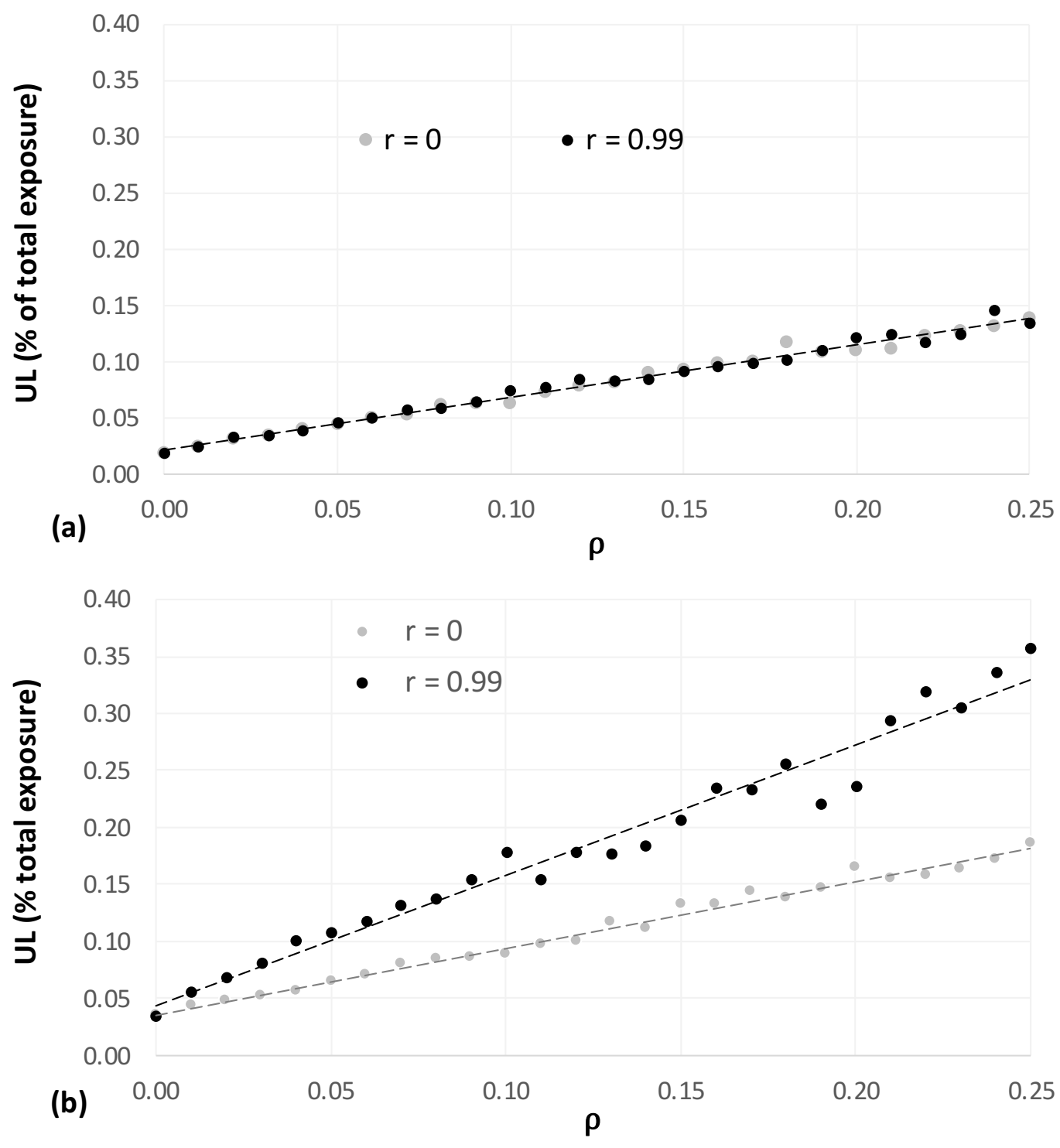

\section{CONCLUSIONS}

Standard EC models were found to be deficient during the credit crisis of 2008, resulting in a significant underestimation of losses and subsequently credit risk. LT proposed an amendment to the RC requirements as set out by the BCBS - namely a stochastic LGD model which incorporates systemic risk, i.e. the state of the economy.

In this article, the LT model was stress-tested for several scenarios. It was found that not only does LT account for systemic risk, but also for the combined effect of this macro-economic loan correlation and the intra-loan correlation, resulting in considerably higher values for both EL and UL when compared to the values obtained for an identical portfolio under Basel regulations. Financial institutions may thus be undercapitalised if Basel RC requirements are blindly followed. Severe undercapitalisation heightens the risk of default and can potentially lead to the collapse of so-called 'financially secure' institutions, an all-too-common occurrence in the credit crisis. The recipe for the 
implementation of the stochastic model was outlined here and the omission of systemic effects on loan losses clearly demonstrated.

Future avenues of research include the exploration of the full range of possibilities for input parameters, here kept constant. Conservative assumptions were made for input parameters including $\mu, \sigma^{2}$ and PD which could be further stressed. For example, lower PDs than used here $(\mathrm{PD}=3 \%)$ are common in bank portfolios, while higher PDs are relevant to only inferior loan books. A wider range of PDs could be explored coupled with the inclusion of systemic, stochastic LGDs. A wider range of empirically observed LGDs could also be included and the impact on loan losses explored.

To test the relevance of these results, actual, empirical losses experienced during the credit crisis could be assembled and the difference between observed ELs (and ULs) and calculated ELs (and ULs) using both the Basel and the LT techniques could be examined. This could help calibrate input parameters for the LT model.

\section{ACKNOWLEDGEMENTS}

This work is based on research supported in part by the Department of Science and Technology (DST) of South Africa. The grant holder acknowledges that opinions, findings and conclusions or recommendations expressed in any publication generated by DST-supported research are those of the author(s) and that the DST accepts no liability whatsoever in this regard.

\section{AUTHOR BIOGRAPHIES}

Jenni van Dyk and Jaun Lange are postgraduate students at the Centre for Business Mathematics and Informatics at the North-West University, Potchefstroom Campus, South Africa.

Gary van Vuuren obtained his $\mathrm{PhD}$ in nuclear physics from the University of Natal, South Africa and then transferred to financial risk management where he completed a $\mathrm{PhD}$ in credit risk management in 2005 . He transferred to the UK in 2003 and has worked in retail banks, asset managers, investment banks, financial consultancies and credit rating agencies. He currently works for Aviva Investors, London, in the model validation group. He is also an extraordinary professor at North West University, South Africa. E-mail: vvgary@hotmail.com

\section{REFERENCES}

Barco, M. (2007). Going downturn. RIsk, 16(8), 70 - 75.

Basel Committee on Banking Supervision (BCBS). (1988). International Convergence of Capital Measurement and Capital Standards. Basel, Switzerland: Bank for International Settlements (BIS).

Basel Committee on Banking Supervision (BCBS). (2006). International Convergence of Capital Measurement and Capital Standards: A Revised Framework (Comprehensive Version). Basel, Switzerland: Bank for International Settlements (BIS).

Basel Committee on Banking Supervision (BCBS). (2013). Fundamental Review of the Trading Book: A Revised Market Risk Framework. Basel, Switzerland: Bank for International Settlements.

Bastos, J. (2010). Forecasting bank loans loss-given-default. Journal of Banking and Finance, 34(10), 2510 - 2517.

Curcio, D., \& Gianfrancesco, I. (2009). Bank Loans Pricing and Basel II: A Multi-Period Risk-Adjusted Methodology under the New Regulatory Constraints. Banks and Bank Systems, 4(4), 66-75.

Dermine, J., \& de Carvalho, C. (2006). Bank loan losses-given default. Journal of Banking and Finance, $30(4), 1219$ - 1243.

Elizalde, A., \& Repullo, R. (2007). Economic and Regulatory Capital in Banking: What Is the Difference? International Journal of Central Banking, 3(3), 87-117.

Esterhuysen, J., van Vuuren, G., \& Styger, P. (2011). The Effect of Stressed Economic Conditions on Credit Risk in Basel II. South African Journal of Economics and Management Sciences, 14(2), 122-137.

FDIC. (2004). Economic Capital and the Assessment of Capital Adequacy. Retrieved April 18, 2016, from https://www.fdic.gov/regulations/examinations/supervisory/insights/siwin04/economic_capital.html

Frye, J. (2004). Loss Given Default and Economic Capital. Capital and MArket Risk Insights, 2004(02), 1-5.

Gordy, M., \& Howells, B. (2006). Procyclicality in Basel II: Can we treat the disease without killing the patient? Journal of financial intermediation, 15(3), 395-417.

Ho, A. (2012, April 18-20). Weaknesses in Regulatory Capital Models and Their Implications. Retrieved February 10, 2016, from www.ermsymposium.org/2012/OtherPapers/Ho-Paper-03-23-12.pdf 
Jürgenson, T. (2015). The Investor's Underestimation of Credit Risk in the Nordic Countries. Estonia: University of Tartu. Jackson, P., Perraudin, W., \& Saporta, V. (2002). Regulatory and "Economic" Solvency Standards for Internationally Active Banks. Journal of Banking Finance, 26(5), 953-976.

Jacobs, J., \& van Vuuren, G. (2014). A Case for Economic Capital as a Pillar 1 Regulatory Tool. South African Journal of Economics, 82(2), 290-314.

Jones, D. (2000). Emerging problems with the Basel Capital Accord: Regulatory capital arbitrage and related issues. Journal of Banking \& Finance, 24(1), 35-58.

Klaassen, P., \& van Eeghen, I. (2009). Economic Capital: How It Works, and What Every Manager Needs to Know. Elsevier. Li, S., \& Tunay, S. (2012). The Impact of Systematic LGD on Economic Capital. Risk Professional, 23-29.

McNeil, A., Frey, R., \& Embrechts, P. (2015). Quantitative risk management: Concepts, techniques and tools. Princeton university press.

Pykhtin, M. (2003). Unexpected recovery risk. Risk, 12(8), 74 - 78.

Richardson, J., \& Stephenson, M. (2000). Some Aspects of Regulatory Capital . London, England: Financial Services Authority (Occasional Papers Series 7).

Saita, F. (2003, March). Measuring Risk-Adjusted Performances for Credit Risk. Working Paper (No. 89). Retrieved March 12, 2016, from http://citeseerx.ist.psu.edu/viewdoc/download?doi=10.1.1.195.6864\&rep=rep1\&type=pdf

Schuermann, T. (2004). What Do We Know About Loss Given Default? Retrieved March 22, 2016, from www.fic.wharton.upenn.edu/fic/papers/04/0401.pdf

Sen, R. (2008). A multi-state Vasicek model for correlated default rate and loss severity. Risk, 18(6), 94 - 100.

Tiesset, M., \& Trousard, P. (2005). Regulatory Capital and Economic Capital. Banque de France Financial Stability Review, 7 , 59-74.

van Laere, E., \& Baesens, B. (2012). Regulatory and economic capital: Theory and practice, evidence from the field. Leuven, Belgium: Doctoral dissertation, Ph.D. dissertation submitted at Kotholieke Universiteit Leuven. Retrieved January 12 , 2015, from

http://www.finanzafirenze.org/irmc/files/regulatory\%20and\%20economic\%20capital\%20theory\%20and $\% 20$ practice $\%$ 20 evidence $\% 20$ from $\% 20$ the $\% 20$ field_van $\% 20$ laere.pdf

Vasicek, O. A. (2002). The Distribution of Loan Portfolio Value. Risk(December), 160-162.

Wang, Y. (2009). Structural Credit Risk Modeling: Merton and Beyond. Risk Management , 16(2), 30 - 33. 